\title{
Hyponatremia in patients with respiratory syncytial virus bronchiolitis
}

This article was published in the following Dove Press journal:

Pediatric Health, Medicine and Therapeutics

28 June 2012

Number of times this article has been viewed

\author{
Hiroaki Kanai' \\ Yuko Sato ${ }^{2}$ \\ Ko Ichihashi \\ 'Department of Pediatrics, Faculty \\ of Medicine, University of Yamanashi, \\ Chuo, Yamanashi; ${ }^{2}$ Department of \\ Pediatrics, Saitama Medical Center, \\ Jichi Medical University, Saitama, Japan
}

Correspondence: Hiroaki Kanai Department of Pediatrics, Faculty of Medicine, University of Yamanashi, Shimokato III I, Chuo 409-3898, Yamanashi, Japan

Tel +8I 482739606

Fax +8I 482736745

Email hkanai@kind.ocn.ne.jp

\begin{abstract}
Children with pulmonary diseases are at risk of developing hyponatremia (serum sodium concentrations $<136 \mathrm{mEq} / \mathrm{L}$ ). The aim of this study was to define the clinical and laboratory characteristics of respiratory syncytial virus (RSV) bronchiolitis in patients with hyponatremia and determine the associated risk factors. Medical data of 105 children ( 56 boys, 49 girls; mean age \pm standard deviation: $9.1 \pm 8.9$ months) with RSV bronchiolitis were retrospectively analyzed. At admission, $35.2 \%$ of all patients, $13 \%$ of the $<12$-month-old patients, and $58.8 \%$ of the $12-35$-month-old patients had hyponatremia. The results show that the development of hyponatremia in inpatients with RSV bronchiolitis is associated with age (12-35 months), body temperature, high fever $\left(\geq 38.5^{\circ} \mathrm{C}\right)$, duration of fever until hospitalization, and high $\mathrm{C}$-reactive protein level at admission. These results indicate that hyponatremia occurs in patients with RSV bronchiolitis exhibiting severe inflammation assessed by fever severity and C-reactive protein level. The use of isotonic fluids is recommended for parenteral therapy of patients with RSV bronchiolitis with risk of developing hyponatremia.
\end{abstract}

Keywords: respiratory syncytial virus, bronchiolitis, hyponatremia, fever, C-reactive protein

\section{Introduction}

Bronchiolitis is the most common lower respiratory infection in infants, ${ }^{1}$ and its most common etiologic agent is respiratory syncytial virus (RSV). RSV bronchiolitis generally has a low mortality rate and only slight morbidity. However, complications such as syndrome of inappropriate secretion of antidiuretic hormone (SIADH) can lead to hyponatremia.

Hyponatremia often develops in acute inflammatory diseases such as meningitis, respiratory tract infections, febrile convulsions, and Kawasaki disease in children. ${ }^{2-5}$ Patients with pneumonia and bronchiolitis, the most common diseases encountered in pediatric general practice, are at particular risk of developing hyponatremia due to antidiuretic hormone (ADH) oversecretion. ${ }^{6-9}$ Some researchers have recently investigated the association between pneumonia and hyponatremia in detail, ${ }^{10-12}$ but there are few reports on the relationship between RSV bronchiolitis and hyponatremia., ${ }^{7,13}$ In particular, the risk factors for developing hyponatremia in RSV bronchiolitis are not well understood.

The aims of this retrospective study were to define the clinical and laboratory characteristics of RSV bronchiolitis in patients with hyponatremia and to determine the risk factors of its development. submit your manuscript | www.dovepress.com

Dovepress

http://dx.doi.org/| 0.2147/PHMT.S33|2|
Pediatric Health, Medicine and Therapeutics 2012:3 39-43

(C) 2012 Kanai et al, publisher and licensee Dove Medical Press Ltd. This is an Open Access article which permits unrestricted noncommercial use, provided the original work is properly cited. 


\section{Patients and methods}

\section{Patients}

The medical records of 107 previously healthy <36-month-old children with RSV bronchiolitis - who were admitted to the authors' medical center between October 2008 and January 2011 because their respiratory status had worsened; their intake of breast milk, diet, or fluid had decreased; and parenteral therapy was required - were retrospectively analyzed. The diagnosis of RSV bronchiolitis was based on an episode of coughing, wheezing, and crackles with RSV positivity in nasopharyngeal secretions using a rapid immunoassay (ImmunoCard STAT ${ }^{\circledR}$ RSV Plus; TFB Inc, Tokyo, Japan). No patient had any underlying disease including renal, thyroidal, hypophyseal, or cardiac insufficiency. Two of the 107 children were excluded due to a partial lack of serum samples at admission.

\section{Clinical data}

The patients' clinical data including age, gender, the duration of fever until hospitalization, respiratory rate, oxygen saturation, and resting body temperature were noted. Fever and high fever were defined as a body temperature of $\geq 37.5^{\circ} \mathrm{C}$ and $\geq 38.0^{\circ} \mathrm{C}$, respectively. Tachypnea was defined as a respiratory rate of $>60$ breaths/minute and $>40$ breaths/ minute in patients $<12$ months old and 12-35 months old, respectively. ${ }^{14}$ All patients received hypotonic fluids for at least 24 hours after admission.

\section{Laboratory data}

Laboratory tests included white blood cell count, serum sodium concentration, creatinine level, and C-reactive protein (CRP) level. Blood sampling was performed at admission before the insertion of any intravenous catheters. As there is currently no consensus on the definition of hyponatremia, it was defined in the current study as a serum sodium concentration of $<136 \mathrm{mmol} / \mathrm{L} .{ }^{15}$ Pneumonia was defined as the presence of infiltration on the chest X-ray.

\section{Statistical analysis}

The data are expressed as the mean (standard deviation) or number (\%). Chi-squared test was used to analyze the categorical variables and the Mann-Whitney U-test was used to compare the two groups. Multivariate analysis was also performed. Values of $P<0.05$ were considered statistically significant.

\section{Results}

The data of 105 patients with RSV bronchiolitis were analyzed (56 boys, 49 girls; mean age \pm standard deviation: $9.1 \pm 8.9$ months). No patient required intensive care, including mechanical ventilation. Figure 1 shows the flow diagram of the patients according to hyponatremic status and age. A total of $35.2 \%(37 / 105)$ of all patients, $13.0 \%(7 / 54)$ of the $<12$-month-old patients, and 58.8\% (30/51) of the 12-35-month-old patients had hyponatremia at admission.

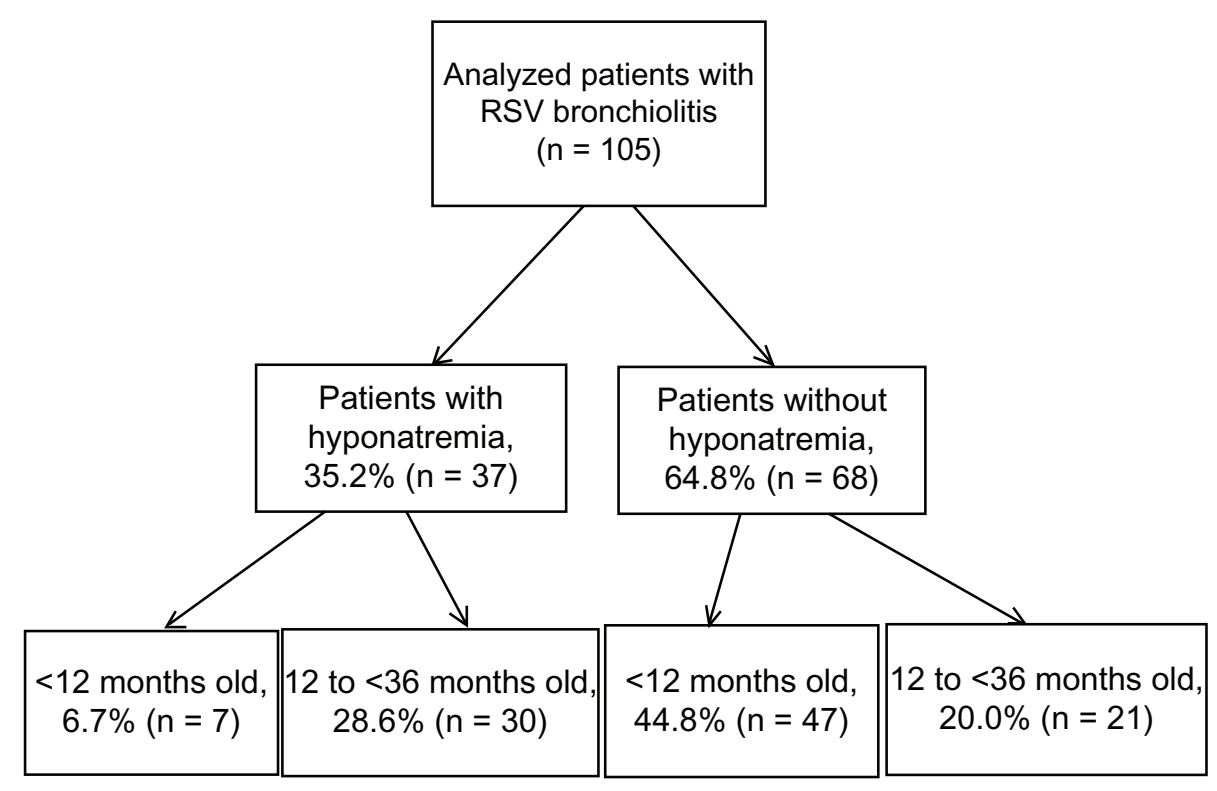

Figure I Patient flow diagram.

Notes: The medical records of 105 previously healthy $<36$-month-old children with respiratory syncytial virus bronchiolitis were reviewed and divided into two groups: those with hyponatremia (35.2\%) and those without hyponatremia (64.8\%). These groups were further divided into two subgroups: < I2-month-old patients and I2-35-month-old patients. Among the patients with hyponatremia, $6.7 \%$ were $<12$ months old and $28.6 \%$ were $12-35$ months old. Among the patients without hyponatremia, $44.8 \%$ were $<12$ months old and $20.0 \%$ were $12-35$ months old. Finally, $35.2 \%$ of all patients and $58.8 \%$ of the I2-35-month-old patients had hyponatremia.

Abbreviation: RSV, respiratory syncytial virus. 
At the time of admission, serum sodium concentrations were 131-141 mEq/L and there were no cases of hypernatremia. Hyponatremia was generally mild, and no patient had a serum sodium concentration of $<130 \mathrm{mEq} / \mathrm{L}$. At admission, $1.9 \%, 12.4 \%$, and $20.1 \%$ of all patients had hyponatremia with a serum sodium concentration of 130 to $<132 \mathrm{mEq} / \mathrm{L}$, 132 to $<134 \mathrm{mEq} / \mathrm{L}$, and 134 to $<136 \mathrm{mEq} / \mathrm{L}$, respectively (Figure 2). The mean serum sodium concentration was $133.8 \pm 1.3 \mathrm{mEq} / \mathrm{L}$ in hyponatremic patients and $137.6 \pm 1.6 \mathrm{mEq} / \mathrm{L}$ in normonatremic patients.

The medical data of the patients with and without hyponatremia at admission was compared (Table 1). Patients with hyponatremia had significantly higher body temperatures at admission $(P<0.01)$ and longer duration of fever until hospitalization $(P<0.01)$. Further, a significantly greater proportion of patients with hyponatremia at admission had a high fever of $\geq 38.5^{\circ} \mathrm{C}(P<0.01)$, presence of fever $(P<0.05)$, and high CRP levels $(P<0.01)$. There were no differences in gender ratio, respiratory rate, presence of tachypnea, oxygen saturation, incidence of pneumonia, creatinine level, and white blood cell count at admission between patients with and without hyponatremia. Multivariable analysis showed that the body temperature at admission and the duration of fever until hospitalization were independent risk factors.

\section{Discussion}

RSV bronchiolitis is a common lower respiratory infectious disease in children that results in hospitalization.
Despite being a well-known complication, hyponatremia has not been widely studied. Several reports on hyponatremia and water metabolism abnormalities including SIADH in children with bronchiolitis were published in the 1990s. Gozal et al prospectively studied 23 consecutive $<12$-month-old hospitalized infants with bronchiolitis. Although they did not mention RSV infection, they found that 22 (96\%) of their patients showed evidence of $\mathrm{ADH}$ hypersecretion and ten (43\%) of the 23 patients had hyponatremia at admission. ${ }^{13}$ In another prospective study, 48 hospitalized infants (median age: 104 days) with RSV bronchiolitis were examined to determine their risk of developing SIADH. ${ }^{9}$ The authors found elevated $\mathrm{ADH}$ levels and serum sodium concentrations of $<135 \mathrm{mmol} / \mathrm{L}$ in $27(56 \%)$ and ten $(21 \%)$ of the 48 infants, respectively. Unlike past reports, the current study enrolled patients with a wider age range (0.5-35 months) and RSV infection; this is because many of the patients with RSV bronchiolitis in the current study were older infants ( $>12$ months old; a total of 13 patients with RSV bronchiolitis were $>24$ months old [data not shown]) and detailed examinations about RSV bronchiolitis in older infants has not been reported previously. Because of these differences, the current data cannot be directly compared with data of past reports, but the authors believe that the findings have greater applicability to pediatric general practice.

In the 1980 s, it was reported that the physiology of hyponatremia in pulmonary disorders was linked to inappropriate ADH secretion in childhood. ${ }^{16-19}$ Furthermore, it was

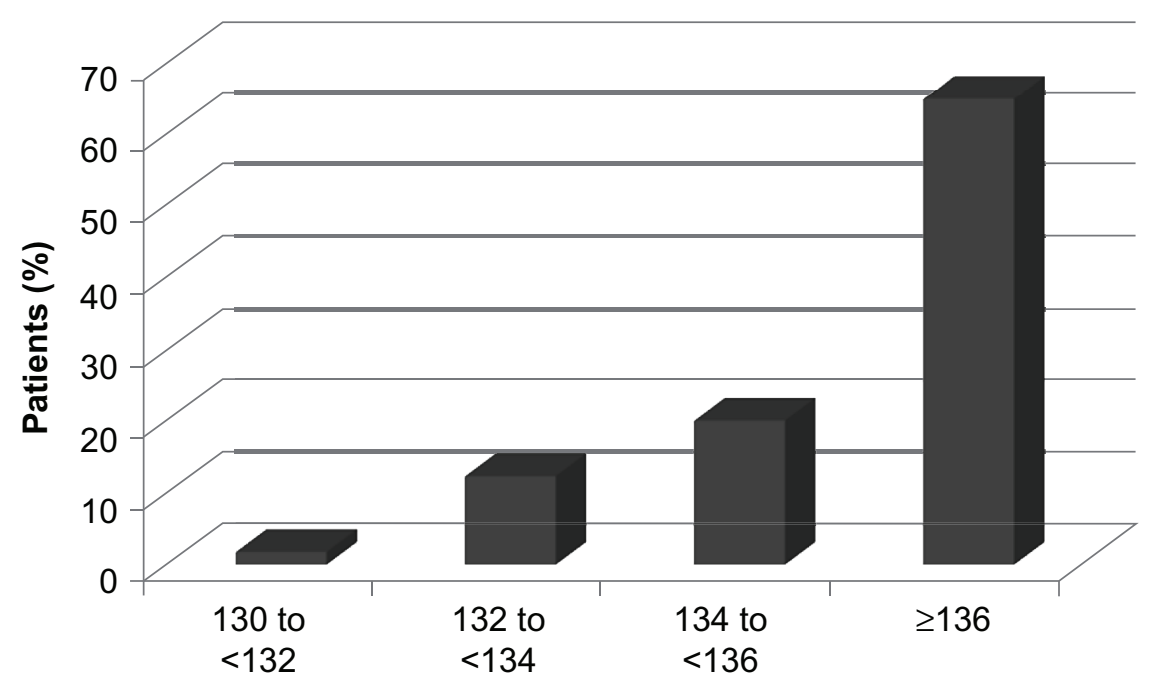

\section{Serum sodium concentration ( $\mathrm{mEq} / \mathrm{L}$ )}

Figure 2 Percentage of patients with various degrees of hyponatremia at admission.

Notes: At admission, serum sodium concentrations were $131-141 \mathrm{mEq} / \mathrm{L}$ and there were no cases of hypernatremia. Hyponatremia was generally mild and no patient had a serum sodium concentration $<130 \mathrm{mEq} / \mathrm{L}$. At admission, $1.9 \%, 12.4 \%$, and $20.1 \%$ of all patients had hyponatremia with a serum sodium concentration of I 30 to $<132 \mathrm{mEq} / \mathrm{L}$, 132 to $<134 \mathrm{mEq} / \mathrm{L}$, and 134 to $<136 \mathrm{mEq} / \mathrm{L}$, respectively. 
Table I Comparison of the clinical and laboratory data according to hyponatremia status

\begin{tabular}{|c|c|c|c|c|}
\hline Characteristics & $\begin{array}{l}\text { Hyponatremia } \\
(n=37)\end{array}$ & $\begin{array}{l}\text { No hyponatremia } \\
(n=68)\end{array}$ & $\begin{array}{l}\text { Univariate analysis } \\
P \text {-value }\end{array}$ & $\begin{array}{l}\text { Multivariate analysis } \\
P \text {-value }\end{array}$ \\
\hline Male patients & $24(64.9)$ & $36(52.9)$ & NS & NS \\
\hline Patients aged $12-35$ months & $30(81.1)$ & $21(30.9)$ & $<0.01$ & NS \\
\hline Body temperature at admission $\left({ }^{\circ} \mathrm{C}\right)$ & $38.8 \pm 1.0$ & $38.0 \pm 0.9$ & $<0.01$ & $<0.01$ \\
\hline Limits of temperature $\left({ }^{\circ} \mathrm{C}\right)$ & $36.2-40.3$ & $36.6-40.6$ & & \\
\hline Presence of fever at admission $\left(\geq 37.5^{\circ} \mathrm{C}\right)$ & 34 (91.9) & $49(72.1)$ & $<0.05$ & \\
\hline High fever $\left(\geq 38.0^{\circ} \mathrm{C}\right)$ & $29(78.4)$ & $31(45.6)$ & $<0.01$ & \\
\hline Duration of fever until hospitalization (days) ${ }^{\mathrm{a}}$ & $4.1 \pm 1.9$ & $3.7 \pm 2.0$ & $<0.01$ & $<0.05$ \\
\hline Respiratory rate (breaths/minute) & $43 \pm 10$ & $47 \pm 11$ & NS & NS \\
\hline Presence of tachypnea & $15(40.5)$ & $28(25.0)$ & NS & \\
\hline Oxygen saturation (\%) & $93.8 \pm 4.1$ & $94.4 \pm 3.7$ & NS & NS \\
\hline Incidence of pneumonia & $9(24.3)$ & $8(I 1.8)$ & NS & \\
\hline Serum sodium concentration $(\mathrm{mEq} / \mathrm{L})$ & $133.8 \pm 1.3$ & $137.6 \pm 1.6$ & $<0.01$ & \\
\hline Creatinine level (mg/dL) & $0.24 \pm 0.05$ & $0.22 \pm 0.04$ & NS & NS \\
\hline WBC count (cells/ $\mu \mathrm{L})$ & $10,640 \pm 4249$ & $10,885 \pm 3386$ & NS & NS \\
\hline$\geq 15,000$ cells $/ \mu \mathrm{L}$ & $2(5.4)$ & $8(11.8)$ & NS & \\
\hline CRP level (mg/dL) & $1.90 \pm 2.63$ & $1.09 \pm 1.55$ & $<0.01$ & NS \\
\hline$\geq 2 \mathrm{mg} / \mathrm{dL}$ & $12(32.4)$ & $9(\mid 3.2)$ & $<0.01$ & \\
\hline
\end{tabular}

Notes: a $O$ the patients who had a fever at admission $(n=75)$. Values represent mean \pm standard deviation or number of patients $(\%)$.

Abbreviations: CRP, C-reactive protein; NS, not significant; WBC, white blood cell.

also reported that levels of ADH are markedly elevated among infants with RSV bronchiolitis during the acute phase, and the levels decrease as the disease process resolves. ${ }^{7,9} \mathrm{ADH}$ is generally secreted by the pituitary gland in response to high plasma osmolality (high serum sodium concentration); however, in various clinical conditions, including fever, hypoxia, hypercarbia, pain, nausea, and vomiting, nonosmotic stimulation of $\mathrm{ADH}$ secretion can lead to hyponatremia. Also, the stimulus of ADH release in pulmonary disease is likely to be nonosmotic; in particular, lung hyperinflation and pulmonary infiltrates may stimulate ADH secretion by causing a false perception of hypovolemia by intrathoracic receptors. ${ }^{13}$ The development of hyponatremia in RSV bronchiolitis requires the presence of both an increased ADH level and a source of electrolytefree water. Infants with RSV bronchiolitis frequently meet

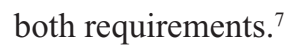

Hasegawa et $\mathrm{a}^{20}$ reported that acute febrile diseases including acute pharyngitis, febrile convulsions, acute bronchitis, pneumonia, and Kawasaki disease in children commonly cause hyponatremia (18\%) due to ADH excess and electrolyte-free water retention; such hyponatremia and $\mathrm{ADH}$ oversecretion are temporally observed in the febrile period and normalize within a week..$^{20}$ Therefore, they suggested that fever is a contributing factor to hyponatremia and that fever and other nonosmotic stimuli directly lead to excess ADH levels and hyponatremia. The current results, indicating that the presence of fever and high fever at admission are risk factors for hyponatremia in RSV bronchiolitis, are similar to those of a past report stating that hyponatremia is significantly more common in febrile patients than in afebrile patients. ${ }^{20}$ Moreover, the patients with hyponatremia in the current study exhibited more severe inflammatory findings (eg, high fever, longer duration of fever until hospitalization, and higher CRP level) than the patients without hyponatremia. These results suggest that fever severity and CRP level at admission are early markers of hyponatremia.

This study has some limitations. ADH levels at admission could not be determined since this measurement is not covered by insurance in Japan; therefore, it is unclear whether SIADH contributed to the development of hyponatremia. However, results of earlier reports suggest that ADH was oversecreted in many patients with hyponatremia in the current study. Since the serum sodium concentration was not measured in most of the patients after parenteral therapy, the degree of change could not be determined. Fortunately, there were no side effects of hyponatremia observed in the current study. However, it is possible that some patients developed asymptomatic hyponatremia.

\section{Conclusion}

The results indicate that mild hyponatremia is common in children with RSV bronchiolitis and its development is associated with age (12-35 months), body temperature, high fever $\left(\geq 38.5^{\circ} \mathrm{C}\right)$, presence of fever at admission, duration of fever until hospitalization, and CRP level. Serum electrolyte 
levels should be measured in all children hospitalized for RSV bronchiolitis, fluid management should be carefully regulated in such patients who develop hyponatremia, and serum sodium concentration should be monitored regularly. Furthermore, the use of isotonic fluids is recommended for parenteral therapy of patients with RSV bronchiolitis who have the risk factors for developing hyponatremia.

\section{Disclosure}

The authors report no conflicts of interest in this work.

\section{References}

1. American Academy of Pediatrics Subcommittee on Diagnosis and Management of Bronchiolitis. Diagnosis and management of bronchiolitis. Pediatrics. 2006;118(4):1774-1793.

2. Sharples PM, Seckl JR, Human D, Lightman SL, Dunger DB. Plasma and cerebrospinal fluid arginine vasopressin in patients with and without fever. Arch Dis Child. 1992;67(8):998-1002.

3. Hugen CA, Oudesluys-Murphy AM, Hop WC. Serum sodium levels and probability of recurrent febrile convulsions. Eur J Pediatr. 1995;154(5): 403-405.

4. Kaneko K, Shimojima T, Kaneko K. Risk of exacerbation of hyponatremia with standard maintenance fluid regimens. Pediatr Nephrol. 2004;19(10):1185-1186.

5. Watanabe T, Abe Y, Sato S, Uehara Y, Ikeno K, Abe T. Hyponatremia in Kawasaki disease. Pediatr Nephrol. 2006;21(6):778-781.

6. van Steensel-Moll HA, Hazelzet JA, van der Voort E, Neijens HJ, Hackeng WH. Excessive secretion of antidiuretic hormone in infections with respiratory syncytial virus. Arch Dis Child. 1990;65(11): 1237-1239.

7. Hanna S, Tibby SM, Durward A, Murdoch IA. Incidence of hyponatraemia and hyponatraemic seizures in severe respiratory syncytial virus bronchiolitis. Acta Paediatr. 2003;92(4):430-434.
8. Dhawan A, Narang A, Singhi S. Hyponatraemia and the inappropriate ADH syndrome in pneumonia. Ann Trop Paediatr. 1992;12(4): 455-462.

9. Szabo FK, Lomenick JP. Syndrome of inappropriate antidiuretic hormone secretion in an infant with respiratory syncytial virus bronchiolitis. Clin Pediatr (Phila). 2008;47(8):840-842.

10. Singhi S, Dhawan A. Frequency and significance of electrolyte abnormalities in pneumonia. Indian Pediatr. 1992;29(6):735-740.

11. Nair V, Niederman MS, Masani N, Fishbane S. Hyponatremia in community-acquired pneumonia. Am J Nephrol. 2007;27(2): 184-190.

12. Don M, Valerio G, Korppi M, Canciani M. Hyponatremia in pediatric community-acquired pneumonia. Pediatr Nephrol. 2008;23(12): 2247-2253.

13. Gozal D, Colin AA, Jaffe M, Hochberg Z. Water, electrolyte, and endocrine homeostasis in infants with bronchiolitis. Pediatr Res. 1990;27(2):204-209.

14. Fleming S, Thompson M, Stevens R, et al. Normal ranges of heart rate and respiratory rate in children from birth to 18 years of age: a systematic review of observational studies. Lancet. 2011;377(9770):1011-1018.

15. Adrogue HJ, Madias N. Hyponatremia. N Engl J Med. 2000;342(21): 1581-1589.

16. Rivers RP, Forsling ML, Olver RP. Inappropriate secretion of antidiuretic hormone in infants with respiratory infections. Arch Dis Child. 1981;56(5):358-363.

17. Shann F, Germer S. Hyponatraemia associated with pneumonia or bacterial meningitis. Arch Dis Child. 1985;60(10):963-966.

18. Dawson KP, Fergusson DM, West J, Wynne C, Sadler WA. Acute asthma and antidiuretic hormone secretion. Thorax. 1983;38(8):589-591.

19. Rao M, Eid N, Herrod L, Parekh A, Steiner P. Antidiuretic hormone response in children with bronchopulmonary dysplasia during episodes of acute respiratory distress. Am J Dis Child. 1986;140(8):825-828.

20. Hasegawa $H$, Okubo $S$, Ikezumi $Y$, et al. Hyponatremia due to an excess of arginine vasopressin is common in children with febrile disease. Pediatr Nephrol. 2009;24(3):507-511.
Pediatric Health, Medicine and Therapeutics

\section{Publish your work in this journal}

Pediatric Health, Medicine and Therapeutics is an international, peerreviewed, open access journal publishing original research, reports, editorials, reviews and commentaries. All aspects of health maintenance, preventative measures and disease treatment interventions are addressed within the journal. Practitioners from all disciplines are invited to submit

\section{Dovepress}

their work as well as healthcare researchers and patient support groups. The manuscript management system is completely online and includes a very quick and fair peer-review system. Visit http://www.dovepress. com/testimonials.php to read real quotes from published authors. 